\title{
Polymerized hexamethyldisilazane coated on equiatomic TiNi shape memory alloy using DC-pulsed plasma assisted chemical vapor deposition
}

\author{
Chien-Hui Chen ${ }^{\mathrm{a}}$, Mu-Rong Yang ${ }^{\mathrm{b}}$, Shyi-Kaan $\mathrm{Wu}^{\mathrm{a}, *}$ \\ ${ }^{a}$ Department of Materials Science and Engineering, National Taiwan University, Taipei 106, Taiwan \\ ${ }^{\mathrm{b}}$ Department of Materials Engineering, Tatung University, Taipei 104, Taiwan
}

Received 23 July 2007; accepted in revised form 29 September 2007

Available online 14 October 2007

\begin{abstract}
$\mathrm{SiC}: \mathrm{H}$ organic-like thin films are deposited on $\mathrm{Ti}_{50} \mathrm{Ni}_{50}$ shape memory alloy by asymmetric bipolar DC-pulsed plasma assisted chemical vapor deposition (PACVD) in the gas mixture of hexamethyldisilazane (HMDSN) and Ar at room temperature. The deposition rate of the plasmapolymerized HMDSN (PPHMDSN) thin film is faster than that of RF process and the PPHMDSN thin films not only enhance the corrosion resistance but make the corrosion current density decay four orders. The surface morphology of the films is very smooth and uniform and the root mean square of surface roughness is in the range between 3 and $5 \mathrm{~nm}$. The organic-like thin films containing peroxides or free radicals can be grafted with polymer acrylamide (AAm) which can improve the biocompatibility of TiNi shape memory alloy.

(C) 2007 Elsevier B.V. All rights reserved.
\end{abstract}

Keywords: TiNi shape memory alloys; HMDSN; Asymmetric bipolar DC-pulsed PACVD; Corrosion resistance improvement

\section{Introduction}

TiNi-based shape memory alloys (SMAs) have the excellent shape memory effect (SME), superelasticity and biocompatibility [1] and have been used as a functional material in a variety of industrial and medical applications such as the intracoronary stent [2], the ligaments' replacement [3], the shape memory microvalve to control drug delivery [4], the bone stamp and osteosynthesis devices [5], etc. The biocompatibility of metal implants is generally evaluated by the reaction between metal and the surrounding tissue. The intensity of the damage caused by metallosis is proportional to the quantity of toxic metallic ions produced by corrosion. In TiNi-based SMAs, titanium is not detrimental among the essential trace elements [6], while nickel proves to exhibit high carcinogenic and toxic potencies in vivo regardless the fact that $\mathrm{Ni}$ is an essential element to the human body [7]. Hence, the passivity current density of the implanted metal in a potentiostatic condition can be taken as an index of the ion release of the metal and this current density is sufficient to be an indicator of its biocompatibility. Since the

\footnotetext{
* Corresponding author. Tel.: +886223637846.
}

E-mail address: skw@ntu.edu.tw (S.-K.Wu). corrosion resistance depends on the surface properties of the alloy, the coatings of plasma-polymerized hexamethyldisilazane (PPHMDSN) are employed in this study to improve the corrosion of $\mathrm{Ti}_{50} \mathrm{Ni}_{50}$ SMA and also to prevent the $\mathrm{Ni}$ ions releasing from $\mathrm{Ti}_{50} \mathrm{Ni}_{50}$ alloy. At the same time, the wettability, the relative wet friction coefficient and the feasibility to graft with polymer to improve their biocompatibility of PPHMDSN coatings on $\mathrm{Ti}_{50} \mathrm{Ni}_{50}$ SMA are also studied and discussed.

\section{Experimental procedure}

\subsection{Substrate preparation}

The $\mathrm{Ti}_{50} \mathrm{Ni}_{50}$ SMA was prepared from titanium (99.8 wt.\%) and nickel (99.98 wt.\%) by using a vacuum/argon tungsten arc furnace. The casting ingot was hot-rolled into 1-mm-thick sheet at $1123 \mathrm{~K}$, and subsequently annealed for $30 \mathrm{~min}$. The rolled sheet was cut into $10 \times 10 \times 1 \mathrm{~mm}$ specimens. The surface was ground on $\mathrm{SiC}$ papers to remove oxide and polished through a standard metallographic procedure to a final level of $1.0 \mu \mathrm{m}$ alumina. Subsequently, all of the polished substrates were cleaned ultrasonically in cleaning reagents (Extran, MERCK Taiwan Ltd.), acetone and ethanol for $10 \mathrm{~min}$ to remove grease 


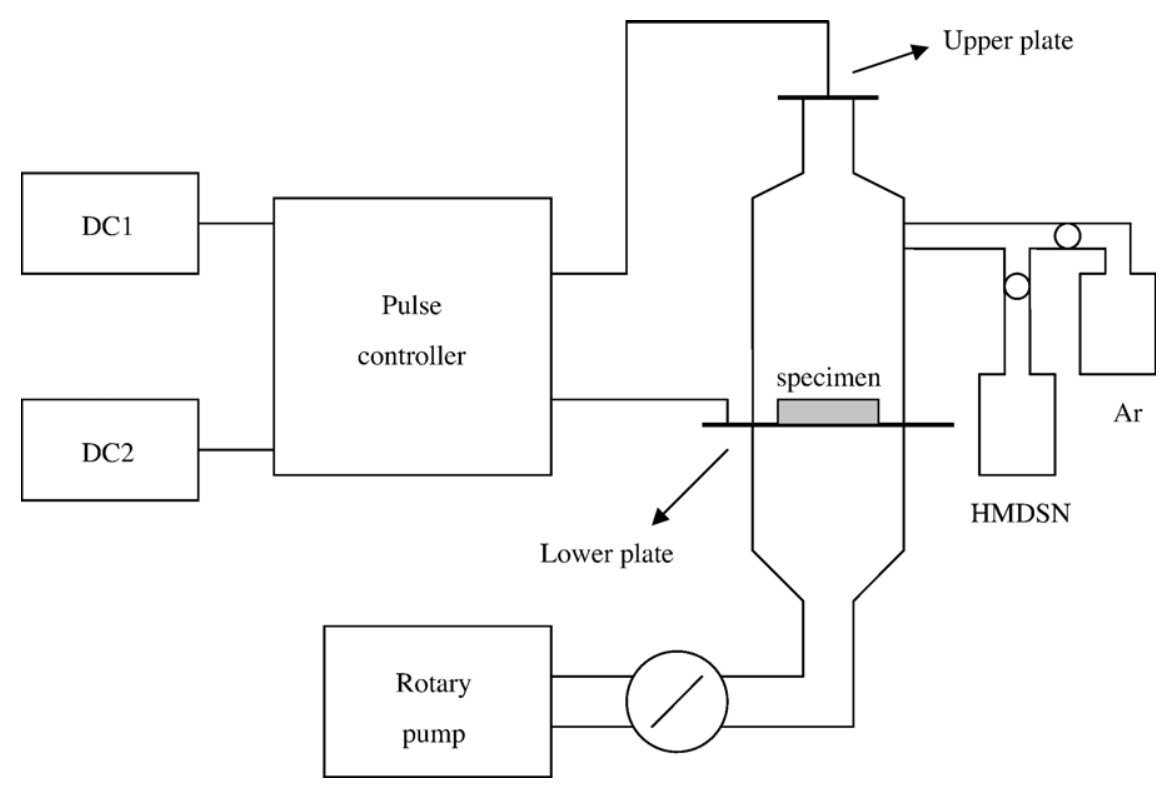

Fig. 1. Schematic diagram of the asymmetric bipolar DC-pulsed PACVD apparatus.

or organic contamination on the surface and then rinsed with deionized water, and finally air dried. These specimens were stored in a dried box before use.

\subsection{Plasma-polymerized HMDSN on TiNi alloy}

The substrate $\left(\mathrm{Ti}_{50} \mathrm{Ni}_{50}\right.$ plate) was placed in the asymmetric bipolar DC-pulsed plasma assisted chemical vapor deposition (PACVD) equipment, as schematically shown in Fig. 1, and connected to a bipolar-pulsed power source [11] of high potential cathode. Plasma deposition was carried out under the given bipolar-pulsed source for 10, 20 and $30 \mathrm{~min}$. The asymmetric bipolar-pulsed DC power is characterized by negative pulse voltage $(V=-800 \mathrm{~V})$ and reverse positive voltage $(V=+600 \mathrm{~V})$. The associated pulsed time of - on, - off, + on, and + off is $300 \mu \mathrm{s}, 10 \mu \mathrm{s}, 100 \mu \mathrm{s}$ and $10 \mu \mathrm{s}$, respectively. Equivalently, frequency of the pulsed wave was $2.38 \mathrm{kHz}$.

The substrates were cleaned in situ prior to deposition by exposing the surface to argon (purity 99.9\%) plasma for $3 \mathrm{~min}$. Hexamethyldisilazane (HMDSN, $\left(\mathrm{CH}_{3}\right)_{3} \mathrm{SiNHSi}\left(\mathrm{CH}_{3}\right)_{3}$, purity $>98 \%, \mathrm{Mw}=161.40 \mathrm{~g} / \mathrm{mol}, \mathrm{bp}=124-127^{\circ} \mathrm{C}, d=0.774 \mathrm{~g} / \mathrm{cm}^{3}$, Fluka Chemical Co. Inc.) is degassed by a freeze-pump-thaw cycle before use. After the system is evacuated to a base pressure of $1.33 \mathrm{~Pa}$ or below, the gas mixed of HMDSN monomer vapor and argon was introduced into the chamber and adjusted to the work pressure of $33.33 \mathrm{~Pa}$ by the continuous monomer vapor flow. The HMDSN monomer has sufficient high vapor pressure at room temperature and, therefore, does not require any external warming. The film formed on the cathode has a highly cross-linked density.

\subsection{Characterization of the deposited films}

Film thickness is determined by the $\alpha$-step method. The measured thickness value is the average of five readings. Static contact angle is measured by ERMA Goniometer (Model G1,
Erma Optical Works Co. Ltd., Japan) at room temperature, $26{ }^{\circ} \mathrm{C}$, and five readings are averaged. Fourier transformation infrared (FTIR) spectra are obtained using a FTIR spectrophotometer (Model A202 Spectrometer, FT/IR-7000, Jasco, UK), to realize the functional groups formed after the glow discharge deposition. The spectra are obtained using a resolution of $4 \mathrm{~cm}^{-1}$ and are averaged over 40 scans.

Potentiodynamic polarization of the specimens is performed on AutoLab PGSTAT30 potentiostat in 278C Ringer's solution (Sintong Chem. Industry Co. Ltd., Taiwan). The composition of Ringer's solution is $\mathrm{NaCl} 8.6 \mathrm{~g} / \mathrm{l}, \mathrm{KCl} 0.3 \mathrm{~g} / 1$ and $\mathrm{CaCl}_{2} \cdot 2 \mathrm{H}_{2} \mathrm{O}$ $0.33 \mathrm{~g} / \mathrm{l}$. The working electrode is a specimen and the potential is imposed on the working electrode vs. the reference electrode (Ag/AgCl electrode). The applied voltage as well as the current flowing between the specimen and the platinum counter electrode is recorded automatically by data acquisition system. The voltage scanned toward the anodic direction until the breakdown potential is reached with the scanning rate of $300 \mathrm{mV}$ per min.

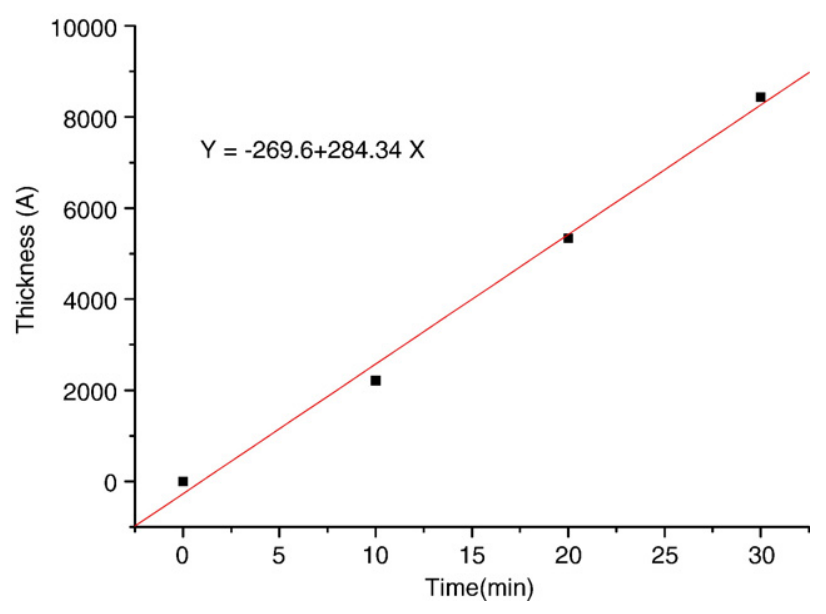

Fig. 2. The figure of the deposition time vs. the thickness of thin film. 


\section{Results and discussion}

\subsection{FTIR characterization of the deposited films}

The deposition rate of SiC:H organic-like (PPHMDSN) thin film deposited on TiNi alloy by asymmetric bipolar DC-pulsed PACVD of hexamethyldisilazane (HMDSN) and Ar gas mixtures is about $284.34 \AA / \mathrm{min}$, as shown in Fig. 2. It is higher more than one order of the deposition process by RF-plasma PACVD, but slower than that by asymmetric bipolar DC-pulsed plasma PACVD [8,9]. Fig. 3 shows the infrared (IR) spectra of PPHMDSN thin films of different deposition time. The IR spectra of HMDSN monomer, as shown in Fig. 3(a), are characterized by the asymmetric $\mathrm{Si}-\mathrm{N}-\mathrm{Si}$ stretching at $939 \mathrm{~cm}^{-1}$, the $\mathrm{Si}-\mathrm{N}$ bending at $1186 \mathrm{~cm}^{-1}$, the $\mathrm{Si}-\left(\mathrm{CH}_{3}\right)_{3}$ stretching vibration at $850 \mathrm{~cm}^{-1}$, the $\mathrm{Si}-\mathrm{CH}_{3}$ rocking at $1258 \mathrm{~cm}^{-1}$, and the stretching vibrations of methyl groups around $2960 \mathrm{~cm}^{-1}, 2923 \mathrm{~cm}^{-1}$ and $2853 \mathrm{~cm}^{-1}$ [10-12]. In contrast to the spectra of PHMDSN film shown in Fig. 3(b)-(d), these absorption intensities of the methyl group obviously increase with increasing the deposition time. In the range of 1200-3000 $\mathrm{cm}^{-1}$, the three most conspicuous characteristic absorption peaks related to $\mathrm{H}$ bonds around $1250-1260 \mathrm{~cm}^{-1}$, $2130 \mathrm{~cm}^{-1}$ and $2960 \mathrm{~cm}^{-1}$ are assigned to the symmetric stretching of $\mathrm{Si}-\mathrm{CH}_{3}, \mathrm{Si}-\mathrm{H}$ and $-\mathrm{CH}_{3}$, respectively. The other absorption peaks are characterized by $\mathrm{Si}-\mathrm{N}$ stretching at $930 \mathrm{~cm}^{-1}, \mathrm{Si}-\mathrm{CH}_{3}$ rocking-stretching at $840 \mathrm{~cm}^{-1}$ and $\mathrm{Si}-\mathrm{C}$ stretching at $790-800 \mathrm{~cm}^{-1}[12-14]$. HMDSN monomer contains no oxygen. However, there is $\mathrm{Si}-\mathrm{O}$ stretching vibration peak at $1020 \mathrm{~cm}^{-1}$. The oxygen in the deposited film may come either from the moisture of the chamber or from the trace impurity in the monomer and argon gas. The related absorption peaks shown in Fig. 3 are listed in Table 1 [15]. The IR spectra show that the origin $\mathrm{Si}-\mathrm{NH}-\mathrm{Si}$ bonds are destroyed

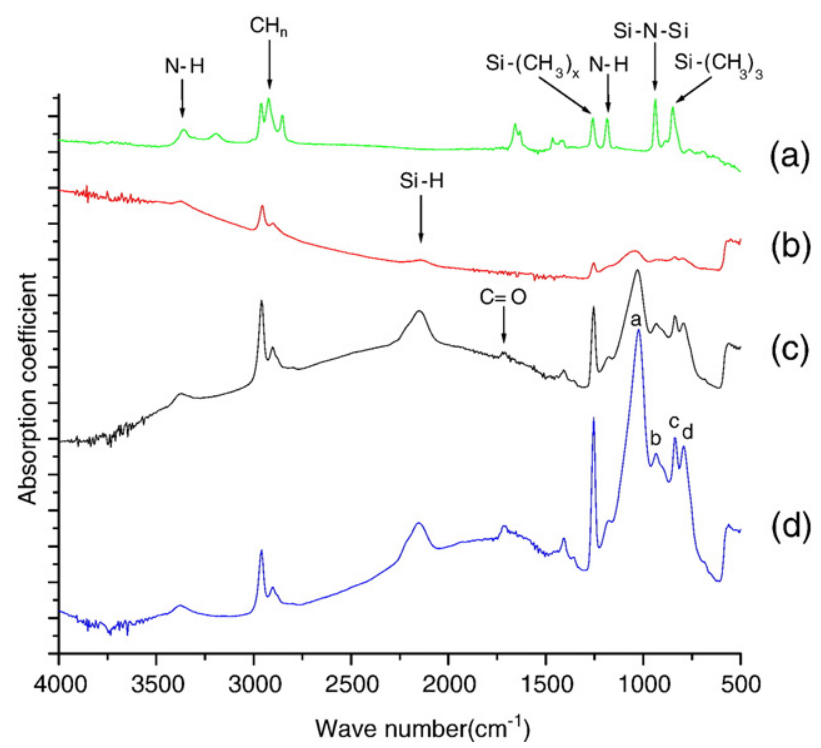

Fig. 3. The IR spectra of (a) the HMDSN monomer, and the PPHMDSN thin films of different deposition time: (b) $10 \mathrm{~min}$, (c) $20 \mathrm{~min}$ and (d) $30 \mathrm{~min}$.
Table 1

The chemical bonds and their related absorption peaks of (a) HMDSN monomer and (b) PPHMDSN thin films shown in Fig. 3

\begin{tabular}{ll}
\hline a) & \\
\hline Chemical bonds & Absorption peak $\left(\mathrm{cm}^{-1}\right)$ \\
\hline $\mathrm{N}-\mathrm{H}$ & 3350 \\
$\mathrm{Si}-\mathrm{N}$ & 900 \\
$\mathrm{Si}-\left(\mathrm{CH}_{3}\right)_{1}$ & 1260,794 \\
$\mathrm{Si}-\left(\mathrm{CH}_{3}\right)_{2}$ & 1260,794 \\
$\mathrm{Si}-\left(\mathrm{CH}_{3}\right)_{3}$ & $1260,794,855$ \\
$\mathrm{Si}-\left(\mathrm{CH}_{3}\right)_{x}$ & 1260 \\
$\mathrm{Si}-\mathrm{C}$ & 790 \\
$-\mathrm{CH}$ & 2960 \\
$-\mathrm{CH}$ & 2900 \\
& \\
$(\mathrm{~b})$ & \\
\hline $\mathrm{Chemical} \mathrm{bonds}$ & \\
\hline $\mathrm{Si}-\mathrm{C}$ & Absorption peak $/ \mathrm{cm}^{-1}$ \\
$\mathrm{Si}-(\mathrm{CH})_{x}$ & 790 \\
$\mathrm{Si}-\mathrm{N}$ & 840,1260 \\
$\mathrm{Si}-\mathrm{O}$ & 939 \\
$\mathrm{Si}-\mathrm{H}$ & 1020 \\
$-\mathrm{CH}$ & 2130 \\
$\mathrm{~N}-\mathrm{H}$ & 2960 \\
\hline
\end{tabular}

by the plasma and formed new bonds, $\mathrm{Si}-\mathrm{H}$, which do not exist in the origin HMDSN monomer.

$\left(\mathrm{CH}_{3}\right)_{3} \mathrm{SiNHSi}\left(\mathrm{CH}_{3}\right)_{3} \stackrel{\mathrm{e}}{\rightarrow} \equiv \mathrm{Si}-\mathrm{CH}_{3}+\mathrm{NH}_{3}$

The $\equiv \mathrm{Si}-\mathrm{CH}_{3}$ will be bombarded by free radical or other high energy particle and dissociated to other structure as following:

$\equiv \mathrm{Si}-\mathrm{CH}_{3} \stackrel{\mathrm{e}}{\rightarrow} \equiv \mathrm{Si} \cdot+\cdot \mathrm{CH}_{3}$

or

$\equiv \mathrm{Si}-\mathrm{CH}_{3} \stackrel{\mathrm{e}}{\rightarrow} \equiv \mathrm{SiCH}_{2} \cdot+\cdot \mathrm{CH}_{3}$

The products of the above equations will react with each other and form silane and methane gas to diffuse out $[12,16]$.

\subsection{Surface property of the deposited films}

Fig. 4(a) shows the cathodic and anodic polarization Tafel curves for the virgin TiNi substrate. The flat portion of the curve, known as the passive region, indicates that the TiNi readily forms a passive film. The open circuit potential (OCP) and the corrosion rate are approximately $0.3740 \mathrm{~V}$ and $0.5696 \mu \mathrm{A} / \mathrm{cm}^{2}$, respectively. However, the reproductivity of the breakdown (pitting) potential for the as-homogenized TiNi is poor and ranges from $0.712 \mathrm{eV}$ to $1.299 \mathrm{eV}$ and gives widely scattered results, as reported in many studies [17-20]. For the PPHMDSN coatings with different deposition time, as shown in Fig. 4(b)-(d), the improvement of corrosion resistance is very remarkable. The fluctuation at the voltage below the breakdown potential is associated with the electrical noise due to the 
(a)

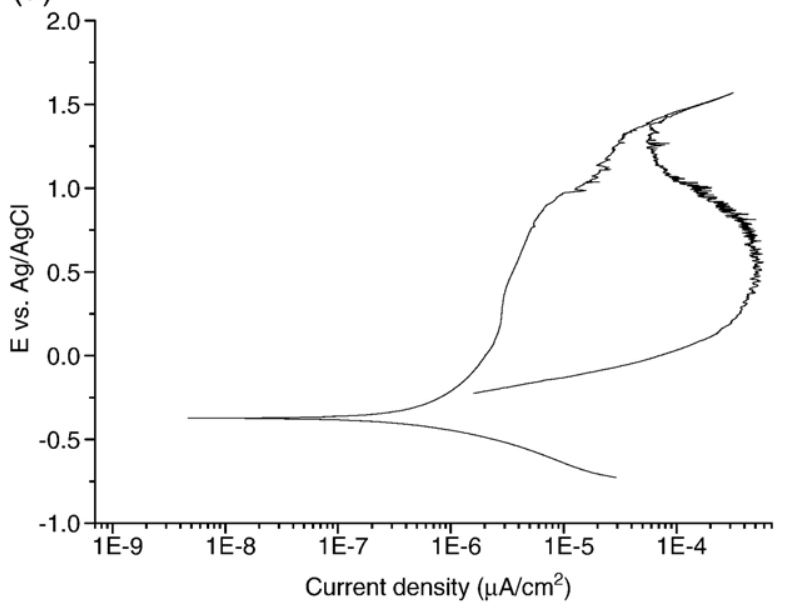

(c)

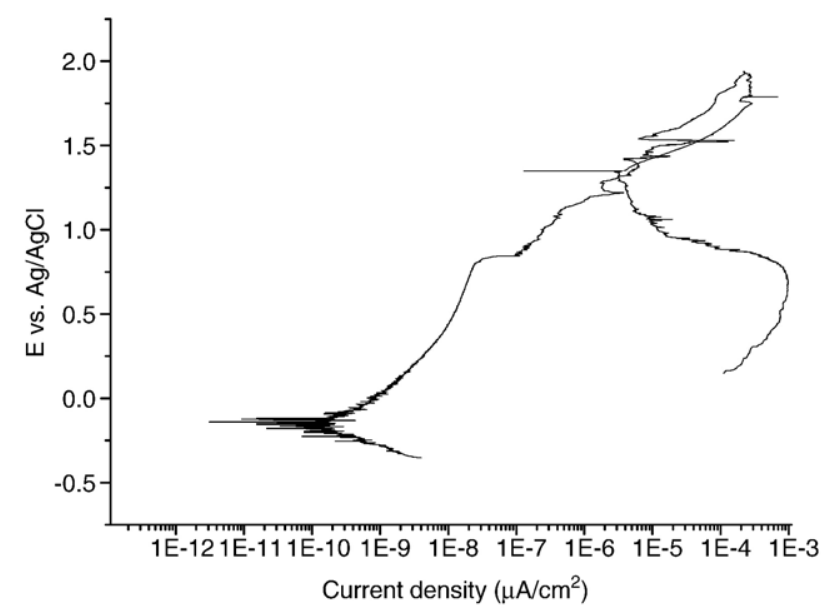

(b)

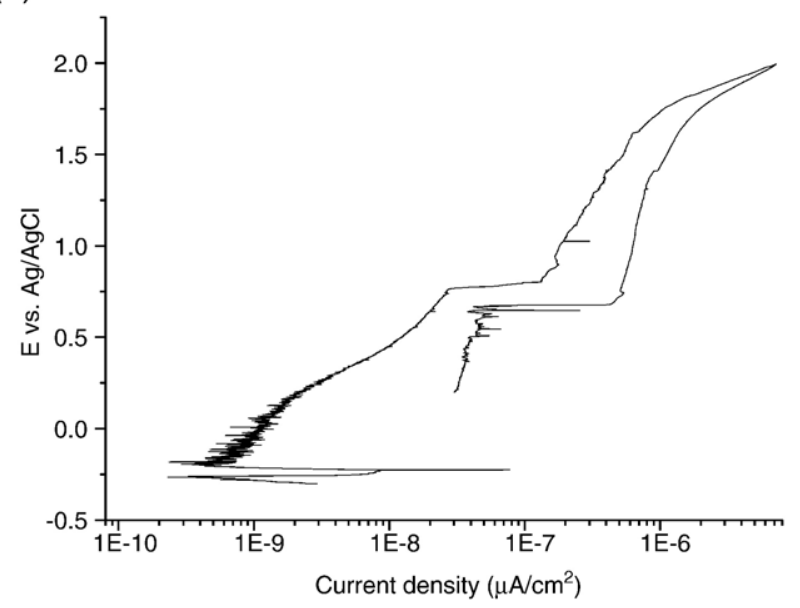

(d)

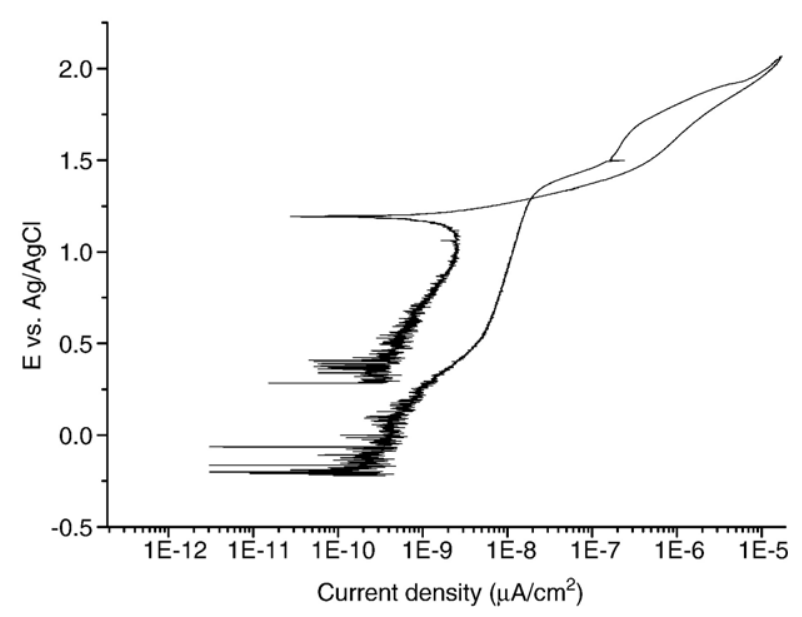

Fig. 4. The cathodic and anodic polarization Tafel curves for the thin films: (a) TiNi substrate, (b) $10 \mathrm{~min}$, (c) $20 \mathrm{~min}$ and (d) $30 \mathrm{~min}$.

resolution limitation of the potentiostat. The PPHMDSN film on TiNi can reduce the current density by at least four orders of magnitude. At the same time, the outstanding improvement shown in Fig. 4(b)-(d) may be attributed to the higher resistance and the more homogeneity (pinhole-free) of the deposited film. The hydrophobic and pinhole-free properties will prevent the TiNi from water uptake, leading to lower ionic conduction by many orders of magnitude. The higher thickness of the PHMDSN film may also account for the substantial improvement.

The wettability of the deposited films can be evaluated from the water contact angle of specimens. The material hydrophility is determined by its chemical structure. The stronger the polarity of the functional groups, the better the affinity with water. The water contact angle of as-polished TiNi alloy is $42^{\circ}$, as indicated in Fig. 5(a). After PPHMDSN deposition, the water contact angle raises from $42^{\circ}$ to $87^{\circ}$, as shown in Fig. 5(b), because the PPHMDSN film consists of more non-polar groups as methyl and methylene.

The other index for evaluating the slippery surface is the wet friction test. Samples with different applied loads were moved onto the wet glass. The lateral force and displacement are measured. The relative wet friction coefficient can be determined from the slope of the linear relationship between the maximum lateral force and the applied load, as the example of deposited PPHMDSN thin film shown in Fig. 6. The relative wet friction coefficient of TiNi alloy is about 0.2217. After deposition of PPHMDSN thin film, the surface becomes more hydrophobic, leading to the increase of relative wet friction coefficient, say, 0.2539. Fig. 7 shows the atomic force microscope (AFM, NTMDT Solver P47) 3D image of PPHMDSN thin films deposited by different time. Under all the experimental conditions, the root mean square of surface roughness of the deposited PPHMDSN thin films measured by AFM is in the range between 3 and $5 \mathrm{~nm}$ (the as-polished roughness is $2.6 \mathrm{~nm}$ ).

\subsection{Possible uses of biocompatibility improvement of the deposited films}

In this study, $\mathrm{SiC}: \mathrm{H}$ organic-like thin films are deposited on TiNi SMA by asymmetric bipolar DC-pulsed PACVD of HMDSN and $\mathrm{Ar}$ gas mixtures at room temperature. However, their hydrophobic surface is disadvantage to medical application. The IR spectra show that the deposited PPHMDSN thin films 
(a)

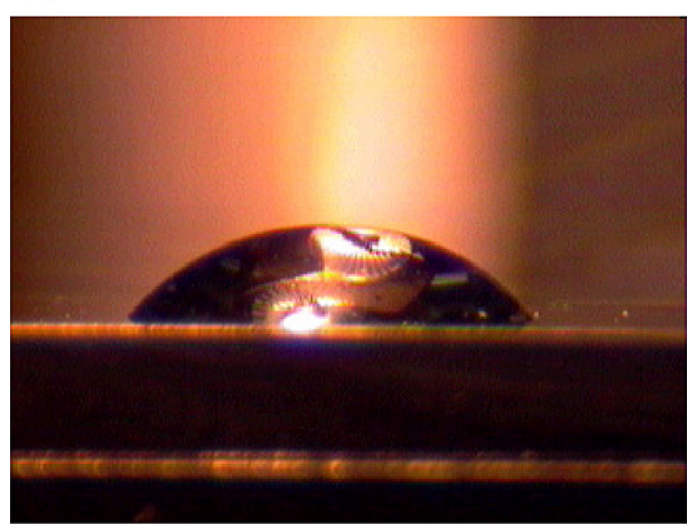

(b)

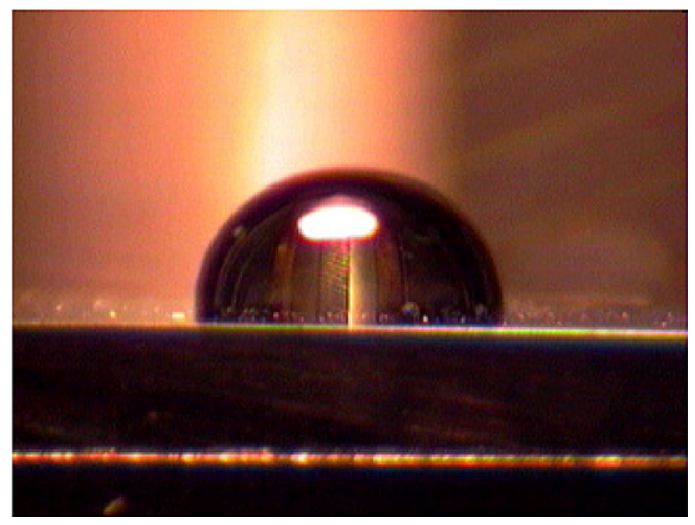

Fig. 5. The water contact angle: (a) measure method, (b) TiNi substrate, and (c) PPHMDSN thin film.

containing peroxides or free radicals can be subsequently grafted with hydrophilic polymer acrylamide (AAm) by UV-induced grafting polymerization [21]. The AAm grafting can be verified from the presence of amide group according to the IR spectra. The slippery property of the coated AAm is beneficial to the biomedical application of TiNi SMAs [21]. For example, heparin can be

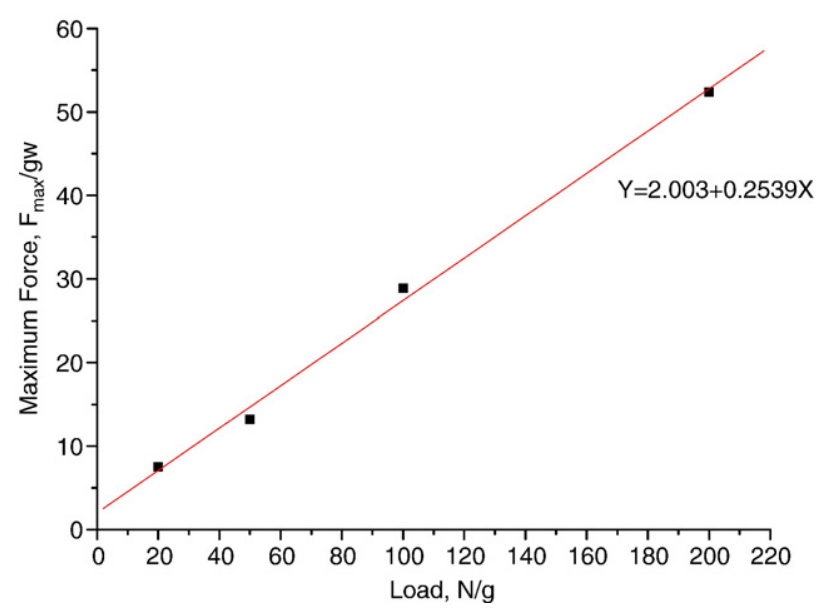

Fig. 6. The wet friction test of the PPHMDSN thin film: the applied load vs. the maximum lateral force.
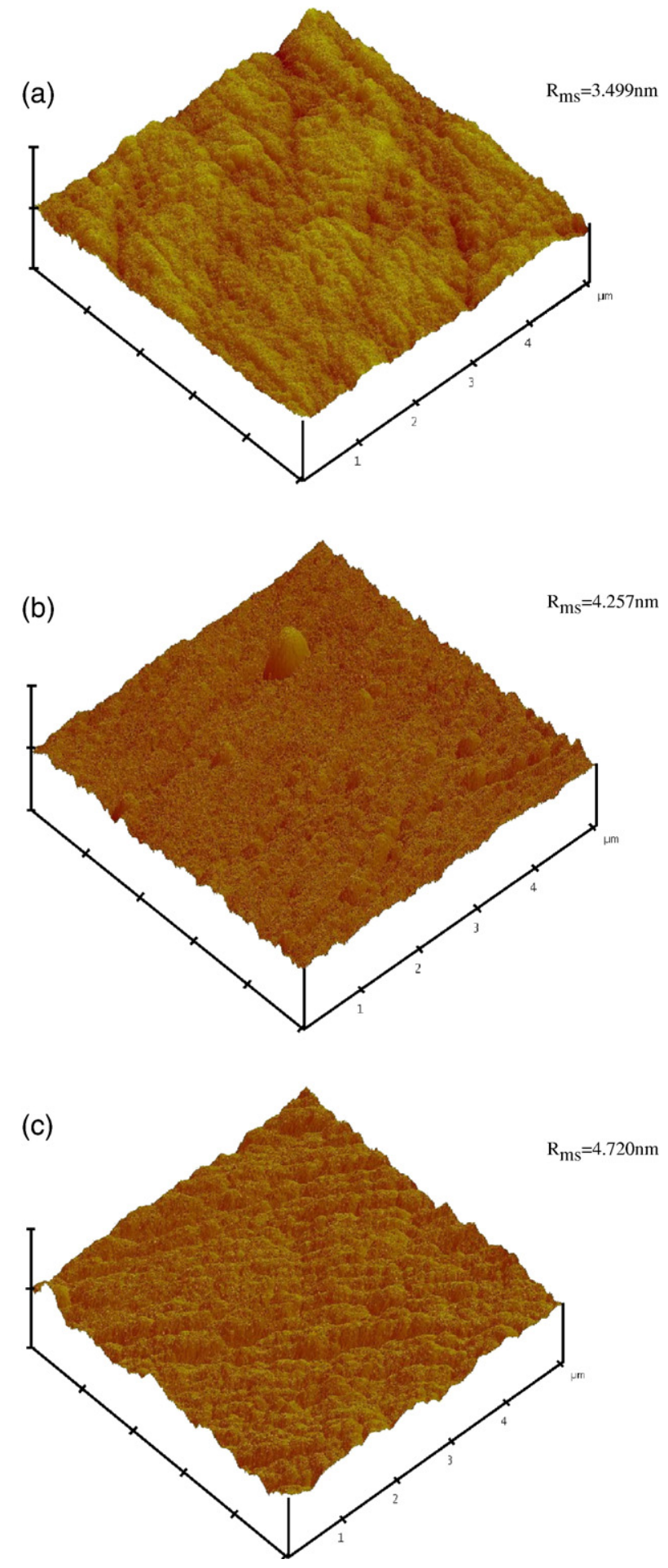

Fig. 7. The AFM 3D image of the PPHMDSN thin films of different deposition time: (a) $10 \mathrm{~min}$, (b) $20 \mathrm{~min}$ and (c) $30 \mathrm{~min}$.

immobilized onto grafted-AAm thin films to take TiNi SMA into the anti-thrombin biomaterials.

\section{Conclusions}

$\mathrm{SiC}: \mathrm{H}$ organic-like thin films are deposited on TiNi shape memory alloys (SMAs) by asymmetric bipolar DC-pulsed 
plasma assisted chemical vapor deposition (PACVD) of HMDSN and Ar gas mixtures at room temperature. The deposition rate of the plasma-polymerized HMDSN (PPHMDSN) thin films is faster than that of RF process and the root mean square of surface roughness is in the range between 3 and $5 \mathrm{~nm}$. The PPHMDSN thin films not only enhance the corrosion resistance but make the corrosion current density decay four orders. Based on the microFTIR spectra, the $\mathrm{Si}-\mathrm{C}$ and $\mathrm{C}-\mathrm{H}$ bonds of the original HMDSN monomer are broken and new $\mathrm{Si}-\mathrm{H}$ and $\mathrm{C}=\mathrm{O}$ bonds are formed. The free radicals react with each other and form silane and methane gas which will diffuse out. After deposition of PPHMDSN thin films, the water contact angle will raise from $42^{\circ}$ to $87^{\circ}$ because the PPHMDSN film consists of more nonpolar groups as methyl and methylene. The surface becomes more hydrophobic, leading to the increase of relative wet friction coefficient. The organic-like thin films containing peroxides or free radicals can be grafted with polymer to improve the biocompatibility of TiNi shape memory alloys.

\section{Acknowledgement}

The authors gratefully acknowledge the financial support of this research from the National Science Council (NSC), Taiwan, under the grant NSC95-2221-E002-164.

\section{References}

[1] C.M. Wayman, T.W. During, in: T.W. During, K.N. Melton, D. Stöckel, C.M. Wayman (Eds.), Engineering Aspects of Shape Memory Alloys, Butterworth-Heinemam, London, 1990, p. 3.
[2] J.L. Longás, J.A. Puértolas, R. Ríos, M.A. de Greogorio, R. Aguirán, SMT-97: Proceeding of the 2nd International Conference on Shape Memory and Superelastic Technology, California, USA, 1997, p. 567.

[3] L'H. Yahia, G. Droin, C.H. Rivard, N. Hagemeister, M. Assad, M. Masson, Biomater. Living Syst. Int. 2 (1994) 79.

[4] D. Reynaerts, J. Peirs, H. Van Brussel, SMT-97: Proceeding of the 2nd International Conference on Shape Memory and Superelastic Technology, California, USA, 1997, p. 555.

[5] S.A. Shabalovskaya, Bio-Med. Mater. Eng. 6 (1996) 267.

[6] F.C. McLean, M.R. Urist, Bone Fundamentals of the Physiology of Skeletal Tissue, 3rd ed. The University of Chicago Press, 1973 p.64.

[7] K. Takaurra, K. Hayashi, N. Ishinishi, T. Yamada, Y. Sugioka, J. Biomed. Mater. Res. 28 (1994) 583.

[8] A.M. Sarmadi, T.H. Ying, F. Denes, Eur. Polym. J. 31 (1995) 847.

[9] M.R. Yang, S.K. Wu, Surf. Coat. Technol. 127 (2000) 274.

[10] S. Eufinger, W.J. van Ooij, T.H. Ridgway, J. Appl. Polym. Sci. 61 (1996) 1503.

[11] M.K. Kim, Thin Solid Films 283 (1996) 12.

[12] M.K. Kim, J. Lee, Thin Solid Films 303 (1997) 173.

[13] A.M. Wrobel, M.R. Wertheimer, H. Dib, H.P. Schreber, J. Macromol. Sci. Chem. 14 (1980) 32.

[14] I. Talima, M. Yamamoto, J. Polym. Sci. Pol. Chem. 23 (1985) 615.

[15] R. González-Luna, M.T. Rodrigo, C. Jiménez, J.M. Martínez-Duart, Thin Solid Films 317 (1998) 347.

[16] J. Weichart, J. Muller, Surf. Coat. Technol. 59 (1993) 342.

[17] Y. Nakayama, T. Yamamuro, Y. Kotoura, M. Oka, Biomaterials 10 (1989) 420.

[18] F. Villermaux, M. Tabrizan, L.H. Yahia, M. Meunier, D.L. Piron, Appl. Surf. Sci. 109-110 (1997) 62.

[19] H. Kimura, T. Sohmura, Dent. Mater. Apparatus 6 (1) (1987) 73.

[20] N.K. Sarkar, W. Redmond, B. Schwaninger, A.J. Goldberg, J. Oral Rehabil. 10 (1983) 121.

[21] C.H. Chen, M.R. Yang, S.K. Wu, Mater. Trans. 48 (3) (2007) 348. 